Canadian

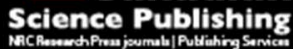

Applied Physiology, Nutrition, and Metabolism Physiologie appliquée, nutrition et métabolisme

\title{
Wild blueberry consumption attenuates local inflammation in the perivascular adipose tissue of obese Zucker rats
}

\begin{tabular}{|r|l|}
\hline Journal: & Applied Physiology, Nutrition, and Metabolism \\
\hline Manuscript ID & apnm-2016-0160.R1 \\
\hline Manuscript Type: & Article \\
\hline Date Submitted by the Author: & $26-$ May-2016 \\
\hline Complete List of Authors: & $\begin{array}{l}\text { Vendrame, Stefano; University of Maine, Food Science and Human } \\
\text { Nutrition } \\
\text { Tsakiroglou, Panagiotis ; University of Maine, Food Science and Human } \\
\text { Nutrition } \\
\text { Kristo, Aleksandra; Istanbul Yeni Yuzyil University, Nutrition and Dietetics } \\
\text { Schuschke, Dale; University of Louisville, School of Medicine } \\
\text { Klimis-Zacas, Dorothy; University of Maine, Food Science and Human } \\
\text { Nutrition }\end{array}$ \\
\hline Keyword: & $\begin{array}{l}\text { PVAT, Blueberries, metabolic syndrome < metabolic syndrome, } \\
\text { inflammation < metabolic syndrome, Endothelial function }\end{array}$ \\
\hline
\end{tabular}


Wild blueberry consumption attenuates local inflammation in the perivascular adipose tissue of obese Zucker rats

Stefano Vendrame, Panagiotis Tsakiroglou, Aleksandra S. Kristo, Dale A. Schuschke, Dorothy Klimis-Zacas

Corresponding author:

Dorothy Klimis-Zacas, PhD, FACN

School of Food and Agriculture, Department of Food Science and Human Nutrition University of Maine, 232 Hitchner Hall, Orono, ME 04469, USA

phone: $207-581-3124$

fax: $207-581-1636$

e-mail: dorothy.klimis@umit.maine.edu

Other authors:

Stefano Vendrame, $\mathrm{PhD}$

School of Food and Agriculture, Department of Food Science and Human Nutrition University of Maine, 232 Hitchner Hall, Orono, ME 04469, USA

email: stefano.vendrame@fulbrightmail.org

Panagiotis Tsakiroglou, MS

School of Food and Agriculture, Department of Food Science and Human Nutrition University of Maine, 232 Hitchner Hall, Orono, ME 04469, USA 
email: panagiotis.tsakiroglou@umit.maine.edu

Aleksandra S. Kristo, $\mathrm{PhD}$

Assistant Professor of Nutrition, Department of Nutrition and Dietetics

Istanbul Yeni Yuzyil University, 26 Yilanli Ayazma Cad.

34010 Cevizlibag Istanbul, Turkey

a.kristo@gmail.com

Dale A. Schuschke, PhD

Professor and Vice Chairman, Applied Physiology and Biophysics

University of Louisville School of Medicine, Louisville, KY 40292, USA,

email: dale.schuschke@,1ouisville.edu 


\begin{abstract}
Perivascular adipose tissue (PVAT) has been shown to play important roles in regulating vascular tone and linking local and systemic vascular inflammation.
\end{abstract}

We examined the impact of PVAT on Phenylephrine-mediated vasoconstriction in the aorta of Obese Zucker rats (OZR) and their lean littermates (LZR), by comparing aortic rings with or without PVAT. Subsequently we placed OZR and LZR on a control (C) or an $8 \%$ wild blueberry (WB) diet and evaluated the effect of WB consumption on such response. PVAT-released adipokine concentrations were also measured as a function of WB diet.

Maximal constrictor force (Fmax) in aortic rings without PVAT was significantly lower in OZRC compared to LZR-C $(0.41 \pm 0.05$ and $0.71 \pm 0.06$ g, respectively). Following WB diet, Fmax significantly increased in OZR $(0.54 \pm 0.06 \mathrm{~g})$. In aortas with intact PVAT, Fmax was significantly lower in all groups $(0.31 \pm 0.06$ OZR-C, $0.30 \pm 0.05$ OZR-WB, $0.29 \pm 0.03 \mathrm{LZR}-\mathrm{C}$ and $0.30 \pm 0.04 \mathrm{~g}$ LZR-WB), but no difference was observed between treatments.

PVAT concentrations of MCP-1, TNF- $\alpha$ and adiponectin were significantly higher in OZR compared to LZR $(+102 \%,+108 \%$, and $+45 \%$, respectively). Following WB diet, PVAT concentrations of IL-8 were significantly lower in both OZR (-37\%) and LZR (-30\%), while adiponectin concentrations significantly increased in both OZR (+11\%) and LZR (+16\%). MCP-1 concentrations significantly decreased $(-31 \%)$ in the PVAT of OZR on WB diet.

Wild blueberry consumption appears to attenuate local inflammation in PVAT, which may impact systemic vascular inflammation and endothelial function. 
Key words:

PVAT ; Blueberries ; Anthocyanins; Metabolic Syndrome ; Inflammation ; Zucker Rat ; Endothelial Function ; Nitric Oxide Synthase ; Cyclooxygenase ; MCP-1; TNF- $\alpha$ 


\section{INTRODUCTION}

The development of endothelial dysfunction and a chronic pro-inflammatory, pro-oxidative, and pro-thrombotic environment are landmark characteristics of Metabolic Syndrome, a cluster of interrelated risk factors which dramatically increase the risk of developing type 2 diabetes and cardiovascular disease (Mozaffarian et al. 2015).

Perivascular adipose tissue (PVAT) is a particular type of adipose tissue with unique characteristics which surrounds larger blood vessels, including the aorta (Gollasch 2012). Besides storing and releasing fat, PVAT also secretes adipokines which act in a paracrine manner on the vascular endothelium and smooth muscle cells, regulating inflammation and endothelial function, which results from an imbalance between vasoconstrictor and vasodilator responses leading to impaired vascular tone and contributing to the development of atherosclerotic lesions (Löhn et al. 2002, Marti et al. 2012). Recent evidence suggest that PVAT is involved in the control of arterial vascular tone by exerting a vasorelaxing activity, although the exact mechanisms and adipokines involved in this action are not clearly understood (Gollasch 2012).

Since obese individuals have more PVAT surrounding their blood vessels, this tissue could play a very important role in understanding some of the different metabolic responses characterizing obesity and Metabolic Syndrome, with particular focus on inflammation and endothelial function (Barandier et al. 2005).

Several lines of evidence have shown that dietary bioactive compounds have the potential of playing important roles in preventing and reversing endothelial dysfunction (Landberg et al. 2012) as well as reducing inflammation (Giugliano et al. 2006). 
Dietary consumption of wild blueberries (WBs), which are among the richest fruit sources of anthocyanins (ACN) and other polyphenols (Häkkinen and Törrönen, 1999), has been repeatedly shown ex vivo to improve the biomechanical properties of rat aortas (Kristo et al. 2010, Kalea et al. 2010, Kristo et al. 2013) and attenuate inflammation (Vendrame et al. 2013).

In previous studies, we have shown that the Obese Zucker rat (OZR), an experimental model of MetS (De Artiñano and Castro 2009), exhibited a reduced vasoconstrictor response to Phe in isolated aortic rings, while WB consumption partially restored such impaired vascular function (Vendrame et al. 2014).

The goal of the present study is twofold. First, we assess the impact of PVAT on Phe-mediated vasoconstriction in the OZR aortic vessel. Subsequently, we evaluate the effect of wild blueberry consumption on such response, including the individual contribution of the nitric oxide synthase (NOS) and cyclooxygenase (COX) pathways. We also measure the effect of WB on the concentrations of four major PVAT-released adipokines: interleukin-8 (IL-8), monocyte chemoactractant protein 1 (MCP-1), tumor necrosis factor alpha (TNF- $\alpha)$ and adiponectin.

The reasoning behind this research is that fat accumulation a major component of metabolic syndrome and obesity results in increased production of PVAT, which induces localized inflammation in the arterial region. In turn, the secretion of pro-inflammatory signaling agents from PVAT induces vascular dysfunction, increasing the risk of cardiovascular disease. Thus, it is reasonable to hypothesize that wild blueberry consumption, by providing its antioxidant and antiinflammatory bioactives, could alleviate the inflammatory burden induced by the hypertrophic PVAT. 


\section{MATERIALS AND METHODS}

\section{Zucker rats}

Thirty-two male obese Zucker rats (OZR) and 32 male lean littermate controls (LZR) were purchased from Charles River laboratories (Raleigh, North Carolina) and divided in two sets, each set consisting of 16 OZR and 16 LZR.

Rats were housed individually in an environmentally controlled room maintained at $22^{\circ} \mathrm{C}$ with a light cycle of 12 hours light and 12 hour dark.

Half of the rats from each group and each set, were randomly assigned to either a wild blueberry enriched diet (WB) or a control diet (C) for 8 weeks, between 8 and 16 weeks of age.

Food and tap water were provided ab libitum. Food intake data were recorded daily and rats were weighed weekly.

The experimental protocol was reviewed and approved by the University of Maine Institutional Animal Care and Use Committee (IACUC).

\section{Wild blueberries}

Wild blueberries were provided as a composite from Wyman's (Cherryfield, ME), freeze-dried, powdered and vacuum-packed by FutureCeuticals (Momence, IL), and stored in the dark at $20^{\circ} \mathrm{C}$ until use. The total anthocyanin content of the WB powder is $1.5 \% \mathrm{w} / \mathrm{w}$, with malvidin 3galactoside and peonidin 3-galactoside as the most abundant anthocyanins, as previously reported (Del Bo' et al., 2010). Total fiber content was 18\% w/w $(15.2 \% \mathrm{w} / \mathrm{w}$ insoluble fiber and $2.8 \%$ $\mathrm{w} / \mathrm{w}$ soluble fiber). Total sugar content was $68.4 \% \mathrm{w} / \mathrm{w}(35.2 \mathrm{w} / \mathrm{w}$ glucose and $33.2 \mathrm{w} / \mathrm{w}$ fructose). 


\section{Diets}

The control diet was prepared mixing $691 \mathrm{~g} / \mathrm{kg}$ dextrose, $200 \mathrm{~g} / \mathrm{kg}$ egg white solids, $60 \mathrm{~g} / \mathrm{kg}$ corn oil, $35 \mathrm{~g} / \mathrm{kg}$ mineral mix (AIN-93M), $10 \mathrm{~g} / \mathrm{kg}$ vitamin mix (AIN-93), 4 g/kg D-L-methionine and $2 \mathrm{mg} / \mathrm{kg}$ biotin. It provided approximately $71 \%$ carbohydrate, $6 \%$ fat, $17 \%$ protein and 403 $\mathrm{kcal} / 100 \mathrm{~g}$. The wild blueberry diet was prepared mixing the same ingredients in the same proportions, except the substitution of $80 \mathrm{~g} / \mathrm{kg}(8 \%)$ wild blueberry powder for an equivalent amount of dextrose. It provided approximately $68 \%$ carbohydrate, $6 \%$ fat, $17 \%$ protein, $1.5 \%$ fiber, $0.12 \%$ anthocyanin and $393 \mathrm{kcal} / 100 \mathrm{~g}$.

\section{Sample collection}

At the end of the dietary period, animals were fasted overnight, anesthetized with $95 \% \mathrm{CO}_{2} / 5 \%$ $\mathrm{O}_{2}$ for 90 seconds, and exsanguinated by intracardiac puncture. The thoracic aorta was excised and cleaned to remove blood clots. In animals from set 1, PVAT was removed from half of the length of the aorta, and the middle part of the aorta was cut into four rings of approximately 3 mm length, in a way that two rings were still surrounded by their PVAT (PVAT + ), and the other two rings were cleaned from it (PVAT-). In animals from set 2, PVAT was left intact so that all four rings were surrounded by it. Rings were immediately used for the evaluation of vasoconstrictor responses, as described below.

The remaining part of the PVAT was rinsed in ice-cold PBS buffer (Sigma) and homogenized with mortar and pestle before adding $5 \mathrm{~mL}$ PBS, vortexing for $1 \mathrm{~min}$, and centrifuging for 15 min at $1500 \mathrm{~g}$. The supernatant was collected, aliquoted and stored at $-80^{\circ} \mathrm{C}$ until further analysis. 


\section{Biomechanical arterial property studies}

The schematic of the experimental design is represented in Figure 1. In animals from set 1, a phenylephrine dose-response curve was generated using four aortic rings with and without PVAT from each animal to evaluate vasoconstrictor responses. Each ring was suspended between two stainless steel weightless wire triangles and mounted in a Radnoti tissue bath (Radnoti Glass Technology Inc., Monrovia, CA) containing PSS at $37^{\circ} \mathrm{C}$ and aerated with a 95\% O2 / 5\% $\mathrm{CO} 2$ gas mix ( $\mathrm{pH} 7.4)$. The bottom triangle was attached to a weightless wire hook fixed to the tissue bath, while the upper triangle was attached to a weightless wire hook connected to a tissue force analyzer (TFA Model 410, Micro-Med Inc., Louisville, KY) to measure the isometric tension (g) developed in the aortic rings during the experiment. The developed force was recorded and analyzed using a personal computer running DMSI-450 software (version 1.01, Micro-Med Inc., Louisville, KY).

After a preload to adjust resting tension to $1.5 \mathrm{~g}$ and a preconditioning (acetylcholine $10-8 \mathrm{M}$ and phenylephrine 10-8 $\mathrm{M}$ for 10 minutes) to saturate non selective receptors, the force was readjusted to baseline (1.5 g) and aortic ring was contracted with six cumulative phenylephrine doses (from 10-8 to 3x10-6 M), and allowed to reach maximum contraction force for 6 minutes after each dose. After the last dose, a single dose of acetylcholine (3x10-6) was added to induce vasorelaxation and confirm the integrity of the endothelium (which was considered acceptable with at least $70 \%$ relaxation). The maximum force of vessel contraction (Fmax) was determined for each ring as the highest value of each phenylephrine curve and was used to evaluate the effect of treatments on aortic contractility. The effective concentration of the agonist to obtain $50 \%$ 
of maximum response (EC50) and vessel sensitivity to the $\alpha 1$-adrenergic receptor response (pD2 $=-\log 10$ EC50) were also determined for each ring (Norton et al., 2005).

In animals from set 2, the same phenylephrine dose-response curve was generated. This time, PVAT was left intact in all aortic rings. Following the preconditioning step, each ring was randomly assigned to either a pre-incubation treatment with L-N-monomethyl-arginine (L-NMMA, $10^{-4} \mathrm{M}$ for 30 minutes), which inhibits nitric oxide synthases (NOS); a pre-incubation treatment with mefenamic acid (MFA, $10^{-5} \mathrm{M}$ for 30 minutes), which inhibits cyclooxygenases (COX); or a treatment with no inhibitor. Force was then re-adjusted to baseline $(1.5 \mathrm{~g})$ before the initiation of the phenylephrine concentration-response experiment, using the same protocol described for set 1 .

\section{Adipokine concentration in PVAT homogenate}

Total protein content in PVAT homogenate was determined using the colorimetric assay "BCA Protein Assay Kit” (ThermoScientific \#23227). Interleukin 8 concentrations in the PVAT homogenate were determined using the "Rat Interleukin-8 ELISA Kit" (MyBioSource \#MBS262974). Monocyte chemoattractant protein 1 concentrations in the PVAT homogenate were determined using the "Monocyte chemoattractant protein 1 ELISA Kit" (MyBioSource \#MBS266051). Adiponectin concentrations in the PVAT homogenate were determined using the "Rat Adiponectin ELISA Kit" (Millipore \#EZRADP-62K). The procedure for the commercially available kits was carried out following the instructions provided by the manufacturer. Spectophotometrical readings were performed on a XMark $^{\mathrm{TM}}$ Microplate Absorbance Spectrophotome- 
ter (BioRad, California). Concentrations of IL-8, MCP-1, TNF- $\alpha$ and adiponectin in the supernatant were standardized to total protein content.

\section{Statistical analysis}

Results from vasoconstriction experiments were evaluated using 2-way ANOVA with StudentNewman-Keuls comparisons on equal numbers of rank-ordered observations, in the absence or presence of inhibitors, in OZR and LZR. Adipokine concentration data were analyzed using 2way ANOVA, with diet (WB vs. C diets) and animal model (OZR and LZR) as independent factors. Significant main effects and interactions were further evaluated by means of the Tukey HSD post hoc test. Statistical analysis was performed using R statistical software version 2.15.1 (R Foundation for Statistical Computing, Vienna, Austria). Results were expressed as means \pm SEM and considered significant at $\mathrm{P}<0.05$. 


\section{RESULTS}

\section{Animal weight and food intake data}

Average weight during the experimental period was significantly higher in OZR $(466.37 \pm 11.98$ g) compared to LZR $(301.64 \pm 8.87 \mathrm{~g})$. Average weight gain between 8 and 16 weeks of age was also significantly higher in OZR $(269.36 \pm 13.88 \mathrm{~g})$ compared to LZR (171.01 $\pm 9.12 \mathrm{~g})$. However, no significant differences for average weight or weight gain were observed within each group between wild blueberry and control rats.

Average food intake was significantly higher in the OZR group $(28.20 \pm 1.45 \mathrm{~g} /$ day $)$ compared to the LZR group $(23.05 \pm 1.36 \mathrm{~g} / \mathrm{day})$, but it was homogeneous within each group between wild blueberry diet and control.

\section{Phenylephrine-induced vasoconstriction with or without PVAT}

The cumulative concentration-response curves to Phe-induced endothelium-dependent vasoconstriction are shown in Figure 2. Maximal constrictor force in the PVAT- rings was significantly lower in OZR (Fmax $0.41 \pm 0.54 \mathrm{~g}$ ) compared to LZR (Fmax $0.71 \pm 0.06 \mathrm{~g})$. In rings with perivascular adipose tissue left attached to the aortic vessel (PVAT+), vasoconstrictor responses were significantly attenuated both in OZR (Fmax $0.32 \pm 0.04 \mathrm{~g}$ ) and LZR (Fmax $0.54 \pm 0.04 \mathrm{~g}$ ) compared to the PVAT- rings.

In presence of PVAT, vessel sensitivity (pD2) to the $\alpha 1$-adrenergic agonist phenylephrine was not significantly different in LZR and OZR (Table 1). When PVAT was removed, pD2 significantly increased in LZR but was unaffected in OZR. 
Phenylephrine-induced vasoconstriction in PVAT+ rings with or without NO and COX pathway inhibition

As shown in Figure 3, Phe-induced vasoconstriction in PVAT + rings was significantly lower in OZR (Fmax $0.33 \pm 0.05 \mathrm{~g}$ ) compared to LZR (Fmax $0.56 \pm 0.09 \mathrm{~g}$ ), while constrictor responses were unaffected by WB in response to all Phe doses in both groups.

When rings were pretreated with NOS inhibitor L-NMMA or with COX inhibitor MFA, the constrictor responses to Phe significantly increased in both OZR (Fmax $1.02 \pm 0.20 \mathrm{~g}$ and $0.54 \pm 0.12$ $\mathrm{g}$, respectively) and LZR (Fmax $1.35 \pm 0.20 \mathrm{~g}$ and $0.87 \pm 0.19 \mathrm{~g}$, respectively). In OZR assigned to WB diet, however, the increase in constrictor responses induced by MFA pretreatment was almost completely abolished (Fmax $0.39 \pm 0.05 \mathrm{~g}$ ), while no such effect was observed in the LZR group. Pretreatment with L-NMMA did not cause any significant variation in vasoconstrictor responses in OZR and LZR assigned to WB diet.

Vessel sensitivity to the $\alpha 1$ adrenergic agonist Phe (Table 2) was similar in OZR and LZR, and was not affected by the WB diet or by MFA-induced COX inhibition. With L-NMMA-induced NOS inhibition, vessel sensitivity significantly increased in both OZR and LZR, independent of $\operatorname{diet}(\mathrm{p}<0.05)$.

Concentrations of inflammatory markers (IL-8, MCP-1, adiponectin, TNF- $\alpha$ ) in PVAT

\section{homogenates}

Concentrations of inflammatory markers in PVAT homogenates are shown in Table 3.

Interleukin-8 concentrations in PVAT homogenates were similar in LZR and OZR, independent of diet. Following wild blueberry consumption, interleukin-8 concentrations were significantly decreased both in LZR (-30\%) and in OZR (-37\%). 
A significant effect of the animal model was observed for MCP-1, TNF- $\alpha$ and adiponectin, whose concentrations were all significantly higher in PVAT homogenates of OZR compared to LZR $(+102 \%,+108 \%$ and $+45 \%$, respectively).

In OZR, a significant model $\mathrm{x}$ diet interaction was found for MCP-1 and TNF- $\alpha$, both of which were significantly lower in the wild blueberry group (-31\% and $-11 \%$, respectively).

Following wild blueberry consumption, adiponectin concentrations significantly increased both in the LZR group and the OZR group $(+16 \%$ and $+11 \%$, respectively). 


\section{DISCUSSION}

The perivascular adipose tissue (PVAT) provides not only structural support and protection for the blood vessels it surrounds, but it is also a metabolically active tissue which releases paracrine mediators directly affecting the vascular endothelium and smooth muscle cells (Greenstein et al. 2012; Gollasch 2012).

Many of the adipokines released by PVAT, such as MCP-1, IL-8, IL-6, TNF- $\alpha$, adiponectin, leptin and resistin, are typically dysregulated in obese people and Metabolic Syndrome patients. Thus, PVAT is a potential target for a better understanding and treatment of these conditions (Gollasch, 2012).

This is the first study attempting to document the role of wild blueberries on local inflammation related to PVAT. The first goal of this study was to determine the impact of PVAT on Phemediated vasoconstriction in the aorta of the obese Zucker rat (OZR), which is a valid experimental model of Metabolic Syndrome (De Artinano and Castro 2009). Consistent with the results we obtained from previous experiments (Vendame et al. 2014), maximal constrictor force was significantly lower in OZR compared to their lean littermates (LZR) in the aortic rings from which PVAT was removed. When PVAT surrounding the aorta was left intact, however, a significant reduction in Phe-induced constrictor responses was observed in both OZR and LZR, suggesting that PVAT indeed acts as a paracrine organ which releases adipokines significantly impacting vascular smooth muscle tone.

This finding is also consistent with a previous report by Löhn et al. (2002), who found that the contractile response to serotonin was significantly reduced in OZR aortic rings when PVAT was left intact, compared to when it was removed. 
The exact mechanisms by which PVAT exerts such anticontractile effects are still not fully understood. Although several adipokines with vasoactive properties have been identified and are released from PVAT, however, none has been proven to play a major role in the vasoregulation of visceral arteries (Gao et al. 2009; Bailey-Downs et al. 2013). Thus, the observed effect may be due to either a synergistic effect of several adipokines, or to a still unidentified adipocyte-derived relaxing factor (ADRF) which acts endothelium-independently and likely activates tyrosine kinase via ATP-dependent K+ channels as reported by Lee et al. (2009).

The next goal of the present study was to determine whether the anti-inflammatory effect of WB exerted locally in the PVAT observed in this study, is reflected in the contractile responses of the aortic vessel when PVAT is left intact during functional mechanical properties experiments.

Following Phe-induced vasoconstriction, OZR again presented with a lower vasoconstrictor responses compared to LZR, but with no differential effect between C and WB treatments. When rings were pretreated with L-NMMA to inhibit NOS, the maximal tension to Phe increased as expected in all groups, but the difference between LZR and OZR remained. The WB diet did not have an effect from control in either animal group. In contrast, when rings were pretreated with MFA to inhibit COX, the increase in constrictor responses was almost completely abolished in OZR assigned to the WB diet.

These results comparing vasodilator pathways show that NO is the primary vasodilator in the aorta of both LZR and OZR phenotypes. Further, when the COX inhibitor MFA is present, the OBZ-WB response to Phe is not augmented like the response seen in the OZR-C or either LZR group. It is not apparent at this point what the mediator of the suppressed response is or how it relates to either the WB diet or the presence of PVAT, or the synergism of the two. 
The biochemical assays conducted in this study in PVAT homogenates, suggest that PVAT of OZR has become dysfunctional, as evidenced by a pro-inflammatory and pro-thrombotic environment with significantly higher concentrations of TNF- $\alpha$ and MCP-1. Wild blueberry consumption appeared to locally attenuate adipokine inflammatory markers in the PVAT of both lean and obese animals.

Interleukin 8 concentrations were significantly lowered in both LZR and OZR following WB consumption. Interleukin 8 is a pro-inflammatory cytokine, mostly produced by activated macrophages, which promotes the expression of adhesion molecules on endothelial cells and whose chronic production leads to endothelial dysfunction (Apostolakis et al. 2009). Kim et al. had already reported that exposure to a black soybean ACN extract for 24 hours was able to decrease IL-8 concentrations in vitro in H. pylori-infected human gastric epithelial cells (Kim et al. 2012). Monocyte chemoattractant protein-1 is a cytokine which is expressed during inflammation and recruits monocytes, promoting their migration and infiltration at the site of active inflammation (Deshmane et al. 2009). When expressed chronically, it exacerbates vascular damage promoting the process of atherosclerosis (Deshmane et al. 2009). In our study, WB consumption resulted in lower MCP-1 concentrations in the PVAT of OZR. Anthocyanins have been already reported an ability to decrease MCP-1 in the adipose tissue. Ju et al. (2011) found that MCP-1 expression was dose-dependently down-regulated in differentiated adipocytes exposed to ACNs from purple sweet potato for 24 hours (Ju et al. 2011); while Sasaki et al. (2007) reported that cyanidin-3glucoside $(0.2 \%)$ fed to diabetic mice for 5 weeks, was able to down-regulate MCP-1 expression in the adipose tissue (Sasaki et al. 2007).

Interleukin-8 and MCP-1 are two major products of PVAT that influence endothelial responses (Gollasch 2012). Both molecules are under transcriptional control of Nf-kB, which we had al- 
ready shown to be down-regulated in the adipose tissue following WB consumption (Vendrame et al. 2013).

In this study, wild blueberry consumption also resulted in significantly higher concentrations of the anti-inflammatory protein adiponectin in the PVAT supernatant of both lean and obese animals. The increase of this humoral vasodilator (Lee et al. 2009) may contribute to the attenuation of the Phe-induced constrictor response in the OZR-WB aortas.

It is to be noted that the vast majority of arterial biomechanical studies are conducted on isolated aortic rings after the PVAT has been removed. However, this study showed that by releasing adipokines, PVAT acts as a paracrine organ significantly impacting endothelial responses. Thus, careful consideration should be given to the option of whether PVAT surrounding blood vessels should be left intact when conducting such studies in order to preserve conditions that are more similar to a physiological state.

In conclusion, this is the first study to show that PVAT exerts an anti-contractile effect in Pheinduced constrictor responses in the aortic vessel of both lean and obese Zucker rats. The PVAT of obese Zucker rats appears to be dysfunctional, with higher concentrations of pro-inflammatory and pro-thrombotic mediators. Furthermore, this study shows for the first time that wild blueberry consumption is able to attenuate local inflammation in the PVAT of OZR. Although this local anti-inflammatory effect was not directly translated in a altered contractile response of the aortic vessel following Phe-induced endothelium-dependent vasoconstriction, it may have important consequences in counteracting the overall pro-inflammatory, pro-oxidative, and pro-thrombotic environment which is characteristic of the development and progression of endothelial dysfunction and Metabolic Syndrome. 
We believe that this line of investigation provides important evidence in developing useful dietary strategies to prevent and reverse the metabolic syndrome, which is of key importance for

public health. Indeed, diet is one of the most manageable ways of preventing the development of metabolic syndrome in the human population, as well as decreasing the risk of complications in patients who already suffer from this condition while greatly reducing the need for pharmacological treatment, which is inevitably associated with harmful side effects and constitutes a considerable financial burden.

\section{CONFLICT OF INTEREST}

The authors declare that there are no conflicts of interest.

\section{ACKNOWLEDGEMENTS}

This work was partially supported by the Wild Blueberry Association of North America and by Hatch Grant no. ME0-8553-09 from the United States Department of Agriculture, National Institute of Food and Agriculture. Maine Agricultural and Forest Experiment Station publication number 3474 . 


\section{REFERENCES}

Apostolakis, S., Vogiatzi, K., Amanatidou, V., Spandidos, D.A. 2009. Interleukin 8 and cardiovascular disease. Cardiovasc. Res. 84(3): 353-60.

Bailey-Downs, L.C., Tucsek, Z., Toth, P., Sosnowska, D., Gautam, T., Sonntag, W.E., et al. 2013. Aging exacerbates obesity-induced oxidative stress and inflammation in perivascular adipose tissue in mice: a paracrine mechanism contributing to vascular redox dysregulation and inflammation. J. Gerontol. A. Biol. Sci. Med. Sci. 68(7): 780-92.

Barandier, C., Montani, J.P., Yang, Z. 2005. Mature adipocytes and perivascular adipose tissue stimulate vascular smooth muscle cell proliferation: effects of aging and obesity. Am. J. Physiol. Heart. Circ. Physiol. 289(5): H1807-13.

De Artiñano, A., Castro, M. 2009. Experimental rat models to study the metabolic syndrome. Br. J. Nutr. 9: 1246-53.

Del Bo’, C., Ciappellano, S., Klimis-Zacas, D., Martini, D., Gardana, C., Riso, P., Porrini, M. 2010. Anthocyanin absorption, metabolism, and distribution from a wild blueberry-enriched diet (Vaccinium angustifolium) is affected by diet duration in the Sprague-Dawley rat. J. Agric.

Food. Chem. 58: 2491-97.

Deshmane, S.L., Kremlev, S., Amini, S., Sawaya, B.E. 2009. Monocyte chemoattractant protein1 (MCP-1): an overview. J. Interferon Cytokine Res. 29(6): 313-26. 
Gao, Y.J., Takemori, K., Su, L.Y., An, W.S., Lu, C., Sharma, A.M., Lee, R.M. 2009. Perivascular adipose tissue promotes vasoconstriction: the role of superoxide anion. Circulation. 119(12): 1661-70.

Giugliano, D., Ceriello, A., Esposito, K. 2006. The Effects of Diet on Inflammation. Emphasis on the Metabolic Syndrome. J. Am. Coll. Cardiol. 48(4): 677- 685.

Gollasch, M. 2012. Vasodilator signals from perivascular adipose tissue. Br. J. Pharmacol. 165(3): 633-42.

Greenstein, A.S., Khavandi, K., Withers, S.B., Sonoyama, K., Clancy, O., Jeziorska, M., et al. 2012. Local inflammation and hypoxia abolish the protective anticontractile properties of perivascular fat in obese patients. J. Gerontol. A. Biol. Sci. Med. Sci. 68(7): 780-92.

Häkkinen, S.H., Törrönen, A.R. 1999. Screening of selected flavonoids and phenolic acids in 19 berries. J. Food. Res. Int. 32: 345-353.

Ju, J.H., Yoon, H.S., Park, H.J., Kim, M.Y., Shin, H.K., Park, K.Y., et al. 2011. Anti-obesity and antioxidative effects of purple sweet potato extract in 3T3-L1 adipocytes in vitro. J. Med. Food. 14: 1097-106. 
Kalea, A.Z., Clark, K., Schuschke, D.A., Kristo, A.S., Klimis-Zacas, D.J. 2010. Dietary enrichment with wild blueberries (Vaccinium angustifolium) affects the vascular reactivity in the aorta of young spontaneously hypertensive rats. J. Nutr. Biochem. 21(1): 14-22.

Kim, S.M., Chung, M.J., Ha, T.J., Choi, H.N., Jang, S.J., Kim, S.O., et al. 2012. Neuroprotective effects of black soybean anthocyanins via inactivation of ASK1-JNK/p38 pathways and mobilization of cellular sialic acids. Life Sci. 90:874-82

Kristo, A.S., Kalea, A.Z., Schuschke, D.A., Klimis-Zacas, D.J. 2010. A wild blueberry-enriched diet (Vaccinium angustifolium) improves vascular tone in the adult spontaneously hypertensive rat. J. Agric. Food. Chem. 58(22): 11600-5.

Kristo, A.S., Kalea, A.Z., Schuschke, D.A., Klimis-Zacas, D. 2013. Attenuation of alphaadrenergic-induced vasoconstriction by dietary wild blueberries (Vaccinium angustifolium) is mediated by the NO-cGMP pathway in spontaneously hypertensive rats (SHRs). Int. J. Food. Sci. Nutr. 64(8): 979-87.

Landberg, R., Naidoo, N., van Dam, R.M. 2012. Diet and endothelial function: from individual components to dietary patterns. Curr. Opin. Lipidol. 23(2): 147-55.

Lee, R.M., Lu, C., Su, L.Y., Gao, Y.J. 2009. Endothelium-dependent relaxation factor released by perivascular adipose tissue. J. Hypertens. 27(4): 782-90. 
Löhn, M., Dubrovska, G., Lauterbach, B., Luft, F.C., Gollasch, M., Sharma, A.M. 2002. Periadventitial fat releases a vascular relaxing factor. FASEB J. 16(9): 1057-63.

Marti, C.N., Gheorghiade, M., Kalogeropoulos, A.P., Georgiopoulou, V.V., Quyyumi, A.A., Butler, J. 2012. Endothelial dysfunction, arterial stiffness, and heart failure. J. Am. Coll. Cardiol. 60(16): 1455-69.

Mozaffarian, D., Benjamin, E.J., Go, A.S., Arnett, D.K., Blaha, M.J., Cushman, M., et al. 2015. Heart disease and stroke statistics - 2015 update: a report from the American Heart Association. Circulation. 131(4): e29-322.

Norton, C., Kalea, A.Z., Harris, P.D., Klimis-Zacas, D.Z. 2005. Wild blueberry rich diets affect the contractile machinery of the vascular smooth muscle in the Sprague-Dawley rat. J. Med. Food. 8: 8-13.

Sasaki, R., Nishimura, N., Hoshino, H., Isa, Y., Kadowaki, M., Ichi, T., et al. 2007. Cyanidin 3glucoside ameliorates hyperglycemia and insulin sensitivity due to downregulation of retinol binding protein 4 expression in diabetic mice. Biochem. Pharmacol. 74: 1619-27.

Vendrame, S., Daugherty, A., Kristo, A.S., Riso, P., Klimis-Zacas, D. 2013. Wild blueberry (Vaccinium angustifolium) consumption improves inflammatory status in the obese Zucker rat model of the metabolic syndrome. J. Nutr. Biochem. 24(8): 1508-12. 
Vendrame, S., Kristo, A.S., Schuschke, D.A., Klimis-Zacas, D. 2014. Wild blueberry consumption affects aortic vascular function in the obese Zucker rat. Appl. Physiol. Nutr. Metab. 39(2): $255-61$. 
Table 1. Vessel sensitivity (pD2) to the alpha1 adrenergic agonist phenylephrine in lean and obese Zucker rats, in the presence (PVAT + ) or absence (PVAT -) of perivascular adipose tissue.

$\begin{array}{lll} & \text { LZR } & \text { OZR } \\ \text { PVAT + } & 6.33 \pm 0.04^{\mathrm{a}} & 6.36 \pm 0.05^{\mathrm{a}} \\ & & \\ \text { PVAT - } & 6.77 \pm 0.05^{\mathrm{b}} & 6.28 \pm 0.13^{\mathrm{a}}\end{array}$

Values are means \pm SEM. $n=8$. Different superscript letters indicate statistically significant differences $(\mathrm{P}<0.05)$. Abbreviations: LZR, lean Zucker rats; OZR, obese Zucker rats. 
Table 2. Vessel sensitivity (pD2) to the alphal adrenergic agonist phenylephrine in lean and obese Zucker rats following control or wild blueberry diet, in the presence of perivascular adipose tissue.

$\begin{array}{lllll} & \text { LZR-C } & \text { LZR-WB } & \text { OZR-C } & \text { OZR-WB } \\ \text { PSS } & 6.44 \pm 0.08^{\mathrm{a}} & 6.37 \pm 0.08^{\mathrm{ab}} & 6.36 \pm 0.07^{\mathrm{ab}} & 6.24 \pm 0.06^{\mathrm{b}} \\ & & & & \\ & & & & \\ & & & & \\ & & & & \\ & 6.70 \pm 0.13 & 6.58 \pm 0.09 \pm 0.09 & \\ \text { PSS+L-NMMA } & 6.38 \pm 0.10 & 6.42 \pm 0.08 & 6.43 \pm 0.08 & 6.35 \pm 0.07\end{array}$

Values are means \pm SEM. $n=8$. Different superscript letters within each row indicate statistically significant differences $(\mathrm{P}<0.05)$. Abbreviations: LZR, lean Zucker rats; OZR, obese Zucker rats; $\mathrm{C}$, control diet; WB, wild blueberry diet; L-NMMA, L-N-monomethyl-arginine; MFA, mefenamic acid. 
Table 3. Concentrations of interleukin (IL)-8, monocyte chemoattractant protein (MCP)-1, tumor necrosis factor (TNF)- $\alpha$ and adiponectin in perivascular adipose tissue homogenates of lean and obese Zucker rats following control or wild blueberry diet.

\section{$\begin{array}{llll}\text { LZR-C } & \text { LZR-WB } & \text { OZR-C } & \text { OZR-WB }\end{array}$}

$\begin{array}{lcrrr}\text { IL-8 (pg/mg protein) } & 901.6 \pm 126.3^{\mathrm{a}} & 628.3 \pm 51.7^{\mathrm{b}} & 944.6 \pm 134.9^{\mathrm{a}} & 598.7 \pm 78.1^{\mathrm{b}} \\ & & & & \\ \text { MCP-1 (ng/mg protein) } & 3.03 \pm 0.70^{\mathrm{a}} & 2.69 \pm 0.61^{\mathrm{a}} & 6.11 \pm 0.65^{\mathrm{c}} & 4.19 \pm 0.40^{\mathrm{b}} \\ & & & & \\ \text { TNF- } \alpha \text { (pg/mg protein) } & 130.0 \pm 22.4^{\mathrm{a}} & 97.0 \pm 17.3^{\mathrm{a}} & 270.4 \pm 53.9^{\mathrm{b}} & 241.0 \pm 33.4^{\mathrm{b}} \\ & & & & \\ \text { Adiponectin (ng/mg protein) } & 170.7 \pm 9.6^{\mathrm{a}} & 197.8 \pm 9.5^{\mathrm{b}} & 247.8 \pm 18.3^{\mathrm{c}} & 275.0 \pm 13.9^{\mathrm{d}}\end{array}$

Values are means $\pm \mathrm{SEM}$, normalized to total proteins. $\mathrm{n}=8$. Different superscript letters within each row indicate statistically significant differences $(\mathrm{P}<0.05)$. Abbreviations: LZR, lean Zucker rats; OZR, obese Zucker rats; $\mathrm{C}$, control diet; WB, wild blueberry diet. 


\section{FIGURE LEGENDS}

Figure 1. Summary of the experimental design.

Figure 2. Phenylephrine concentration-response curves in lean (LZR) and obese (OZR) Zucker rats, in absence (PVAT -) or presence (PVAT + ) of perivascular adipose tissue ( $\mathrm{n}=8$ per group). Different letters indicate statistically significant differences within each Phe concentration $(\mathrm{P}<0.05)$

Figure 3. Phenylephrine (Phe) concentration-response curves in lean (LZR) and obese (OZR) Zucker rats following a wild blueberry (WB) or control (C) diet (n=8 per group). Force of contraction was measured in aortas in presence of perivascular adipose tissue, in PSS alone, with the addition of L-N-monomethyl-arginine (L-NMMA, $\left.10^{-4} \mathrm{M}\right)$ or mefenamic acid $\left(\mathrm{MFA}, 10^{-5} \mathrm{M}\right)$. Different letters indicate statistically significant differences within each Phe concentration $(\mathrm{P}<0.05)$. 


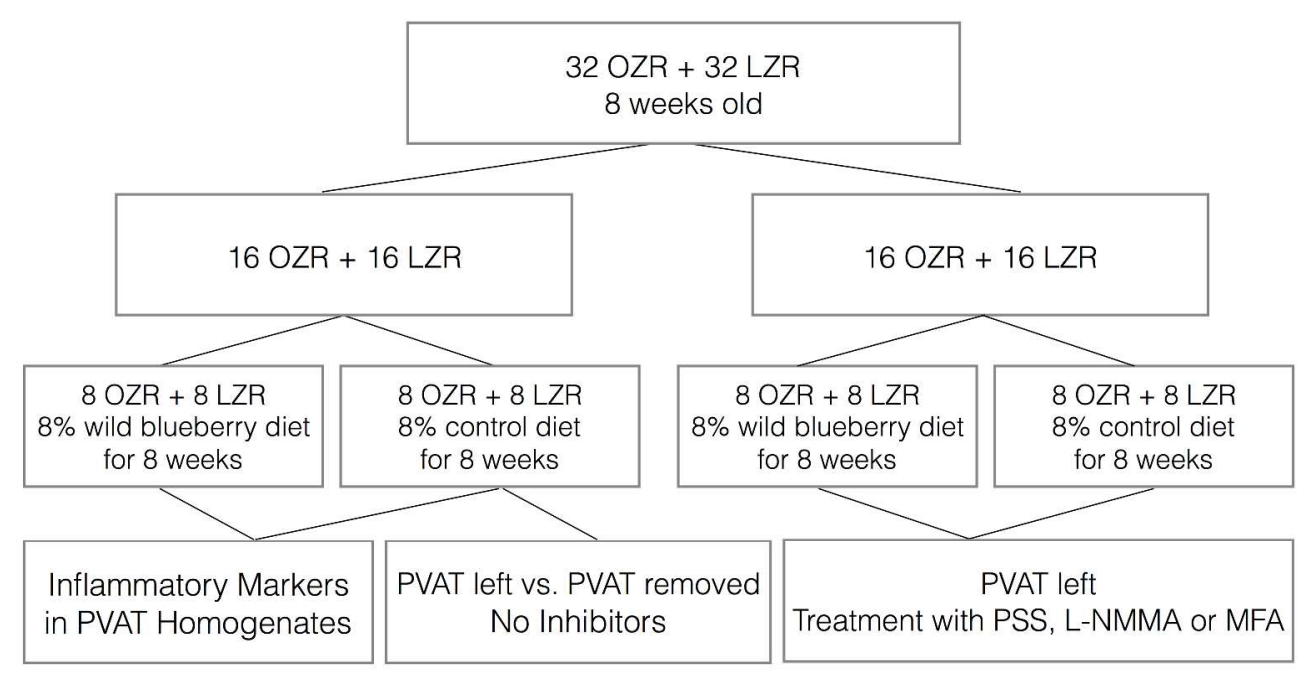

$354 \times 182 \mathrm{~mm}(300 \times 300 \mathrm{DPI})$ 


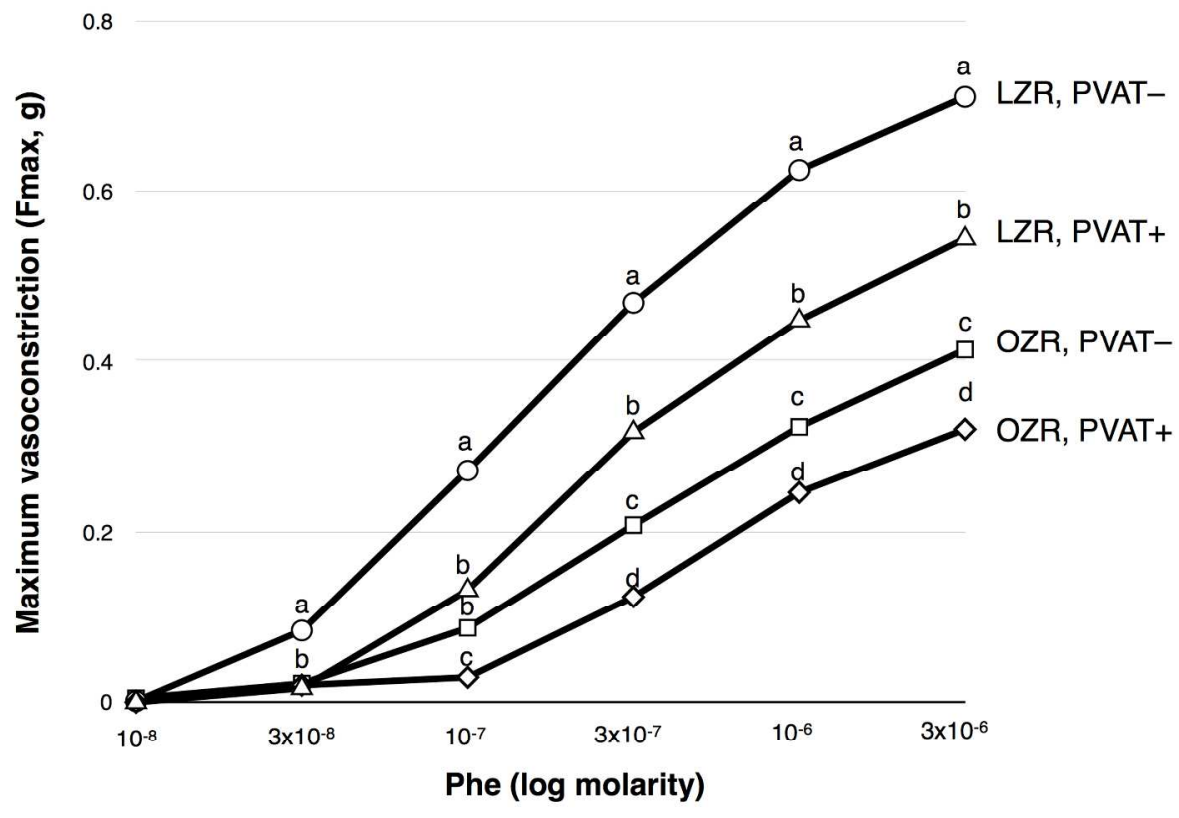

$208 \times 150 \mathrm{~mm}(300 \times 300 \mathrm{DPI})$ 

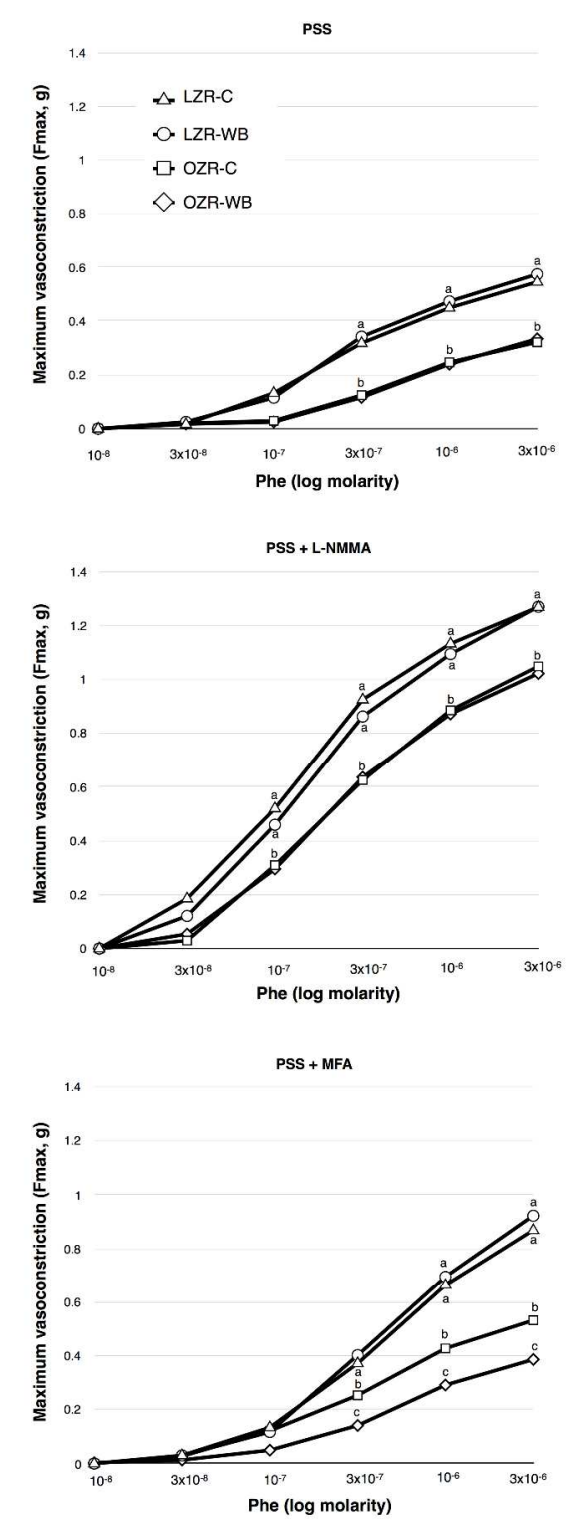

$171 \times 453 \mathrm{~mm}(300 \times 300 \mathrm{DPI})$ 